\title{
A NIP DA ANS E A EFICIÊNCIA ADMINISTRATIVA NA RESOLUÇÃO DE LITÍGIOS DA SAÚDE SUPLEMENTAR
}

\author{
SIMONE SANCHES FREIRE ${ }^{1}$ \\ EduARDO CHOW DE MARTINO TOSTES ${ }^{2}$
}

\begin{abstract}
RESUMO: O presente artigo busca explorar tema de grande complexidade nas relações de consumo envolvendo a questão de saúde suplementar. Em especial, a denominada Notificação de Intermediação Preliminar (NIP) da Agência Nacional de Saúde (ANS) e os seus efeitos para a resolução de litígios do consumo e contribuição para a redução da assimetria da informação do órgão regulador perante as empresas reguladas. Trata-se de uma pesquisa exploratória, de maneira retrospectiva, que busca responder a seguinte questão-problema: qual o papel da NIP? A hipótese defendida neste trabalho passa pela afirmação de que a Notificação de Intermediação Preliminar é um modelo de sucesso a título de solução extrajudicial do conflito, além de ser um relevante mecanismo de insumo regulatório por possuir incentivos ímpares para as questões conflituosas postas a sua análise, dentro de seu escopo de abrangência. $O$ objetivo do presente trabalho almeja refletir modelos inspiradores de soluções de conflitos no cenário brasileiro. Sua metodologia perpassa pela análise de dados da ANS, de processos judiciais, além de pesquisa bibliográfica afeta à temática. $\mathrm{O}$ resultado da presente pesquisa convida o leitor a não somente desejar um aprofundamento das questões inerentes à NIP na ANS, mas também a reflexões amplas e necessárias no panorama atual de uma intensa judicialização de questões consumeristas em temas diversos.
\end{abstract}

Palavras-Chave: NIP; ANS; Resolução de Conflito; Assimetria de Informação; Eficiência Administrativa.

\footnotetext{
${ }^{1}$ Mestranda pela EAESP FGV. Diretora de Fiscalização da ANS dos períodos 2014/2017 e 2017-2020. Especialista em regulação de saúde suplementar. Advogada.

2 Doutorando e Mestre pela UFF. Professor convidado da pós-graduação lato sensu da UFF, PUCRio e UCAM. Defensor Público do Estado do Rio de Janeiro.
} 
ABSTRACT: This article seeks to explore a topic of great complexity in consumer relations involving the issue of supplementary health. In particular, the so-called Preliminary Intermediation Notification (NIP) of the National Health Agency (ANS) and its effects for the resolution of consumer disputes and for the reduction of the asymmetry of the information of the regulatory body before the regulated companies. This is a retrospective exploratory research that seeks to answer the following problem question: what is the role of the NIP? The hypothesis defended in this paper is the statement that the Preliminary Intermediation Notification is a model of success as an extrajudicial solution to the conflict and as a mechanism for regulatory input because it has unique incentives for the conflicting issues put to its analysis, within its scope. The aim of this paper aims to reflect inspiring models of conflict solutions in the Brazilian scenario. Its methodology involves a thorough analysis of ANS data, legal proceedings, in addition to bibliographic research affecting the subject. The result of this research invites the reader to not only wish to deepen the issues inherent to the NIP in ANS, but also to broad and necessary reflections in the current panorama of an intense judicialization of consumer issues in different themes.

KeYWORDS: NIP; ANS; Conflict Resolution; Information Asymmetry; Administrative Efficiency.

\section{INTRODUÇão}

A Notificação de Intermediação Preliminar - NIP, é um instrumento regulatório com múltiplas funções, dentre as quais destacamos as de resolução de conflitos da saúde suplementar e de diminuição da assimetria de informações entre a ANS e as Operadoras de Planos de Saúde (OPS), de forma direta, e, indiretamente, entre os beneficiários e as empresas

Como se trata de um instituto com características diferenciadas, como adiante nos debruçaremos, o referido procedimento foi alvo tanto de ações que questionaram sua legalidade e de estudos científicos que buscaram compreender sua função.

Por meio desta pesquisa, buscaremos responder a seguinte questão-problema: qual o papel da NIP? E a hipótese defendida neste trabalho passa pela afirmação de que a Notificação de Intermediação Preliminar é um modelo de sucesso a título de solução extrajudicial do conflito e de mecanismo de insumo regulatório por possuir incentivos ímpares para as questões conflituosas postas a sua análise, dentro de seu escopo de abrangência.

O método para o desenvolvimento deste trabalho é o hipotético dedutivo, com a utilização de instrumentos metodológicos necessários para a verificação da afirmação da hipótese, e, para tanto, passou por uma necessária análise de dados junto à ANS, processos e indicadores judiciais, além de pesquisa bibliográfica. Trata-se de pesquisa que tenta aliar a teoria e a prática, à luz da experiência 
profissional dos autores, como forma de se obter resultados científicos pragmáticos e replicáveis para a ciência do Direito e da Regulação.

O primeiro capítulo busca conceituar e trazer o desenvolvimento histórico da NIP no cenário nacional, a partir de dados coletados junto à ANS e de processos judiciais que questionaram sua validade perante o Poder Judiciário. Nesta primeira parte, lançamos mão da análise da NIP como um eficiente modelo de redução de assimetria de informações da ANS perante as OPS.

O segundo capítulo se desenvolve na abordagem da temática da judicialização da saúde suplementar e a sua relação com a NIP. Trata-se de importante pesquisa relacionando este instrumento com os números do $\mathrm{CNJ}$ (Conselho Nacional de Justiça) e os parâmetros de resolutividade, a partir da análise de dados da ANS sobre questões resolvidas extrajudicialmente nas temáticas passíveis de consideração pela NIP.

Ao final, almeja-se, para além de se apresentar um modelo de eficiência regulatória e de sucesso na resolução de conflitos extrajudiciais, objetiva-se refletir sobre modelos inspiradores de soluções de litígios em outros cenários no mercado de consumo brasileiro, a partir de balizas dispostas neste trabalho.

\section{ORIGEM DA NIP - UM MODELO EFICIENTE DE REGULAÇÃO DIMINUINDO ASSIMETRIA DE INFORMAÇÃO PARA OS CONSUMIDORES E À AGÊNCIA}

A NIP é um procedimento regulatório da ANS com a dupla função de resolução de conflitos entre beneficiários e OPS, funcionando como propulsora de ações fiscalizatórias pelo órgão regulador, além da função de monitoramento do mercado de saúde suplementar.

Desta forma, não é possível compreender a NIP em uma visão restrita de somente um procedimento de solução de conflitos, como muitos autores a definem (UNES, 2018, p. 12; SALVATORI e VENTURA, 2012, p. 479; CARVALHO et al, 2018, p. 381 e 382). A função de monitoramento de mercado pela NIP será explorada devidamente nas próximas linhas.

A NIP foi instituída na ANS no ano de 2008, através de um projeto piloto com algumas operadoras de planos de saúde que foram voluntárias. Em 2010, através da RN (Resolução Normativa) n. 226, a ferramenta foi normatizada, mantendo o caráter voluntário de adesão por parte das OPS e restrita às reclamações de consumidores que relatassem negativas de cobertura assistencial. Nessa norma, a sigla NIP significa Notificação de Investigação Preliminar e difere completamente do que se entende da notificação atualmente.

Através da RN 343, de 2013, a notificação passou a ser obrigatórias para as operadoras de planos de saúde, e teve sua atuação ampliada para todos os casos reclamados pelos beneficiários. Essa norma, que entrou em vigor apenas em março de 2014, mudou a nomenclatura da ferramenta, que passou a se chamar notificação de intermediação preliminar, reforçando seu caráter pré-processual e de instrumento de resolução de conflitos. A RN 388, de 2015, ampliou e dinamizou o 
alcance do NIP, e a RN 444, de 2019, aperfeiçoou o mecanismo, sendo essas duas normas as que regem a matéria até a presente data.

Trata-se de um procedimento extrajudicial, que não se confunde com um processo administrativo em seu sentido estrito, por não comportar em sua estrutura arquitetônica todos os elementos do contraditório e ampla defesa inerentes à conceituação prevista no art. $5^{\circ}$, LV da Constituição Federal, sendo classificada como fase pré-processual.

Desta forma, não se verifica a possibilidade de o procedimento da NIP ser o meio para uma sanção a ser aplicada pela ANS, como pode parecer em um primeiro momento. ${ }^{3} \mathrm{~A}$ própria modificação da nomenclatura, o que reforça o caráter não sancionador da NIP.

O monitoramento do mercado realizado pela ANS através da NIP é uma função das mais importantes decorrentes deste instrumento regulatório, a fim de se reduzir a assimetria de informação no setor. Compreender como o mercado está funcionando, à luz das informações direcionadas à ANS pelos consumidores, é um subsídio importantíssimo para que a Agência reguladora conheça o comportamento do mercado e das operadoras individualmente, inclusive para avaliar e determinar ações visando correção de conduta, que podem ser sistêmicas, quando, por exemplo, os dados das reclamações são utilizados para a construção de novas normas, ou focais, quando são utilizados para instauração de procedimentos que visem alterar a forma como uma empresa está se posicionando no atendimento de seus consumidores.

De acordo com Miraldo:

A lógica utilizada pela ANS para o bloqueio de comercialização de planos é que se uma operadora é alvo de um número elevado de demandas NIP, em determinado ciclo de monitoramento, há indícios que sua rede credenciada ou seus serviços assistências não são suficientes para atender a seus beneficiários, portanto, não deve ser permitido o aumento de carteira por meio de vendas. Para adequar esta relação foi idealizada a proibição da comercialização destes planos, comercialização esta que só volta a ser permitida pela ANS quando for verificado que a normalidade no atendimento foi restabelecida, por meio da diminuição das reclamações (2016, p. 55).

\footnotetext{
${ }^{3}$ Em uma outra interpretação, Miraldo: "As notificações de intermediação preliminar além de causar impacto nos índices monitorados e divulgados pela ANS, conforme já exposto, podem afetar diretamente a operadora de planos de saúde devido a previsão legal (RN 388) de uma série de medidas administrativas, caso o seu Índice de Reclamações fique acima da médica do setor, entre elas multa pecuniária e, mais grave ainda, a suspensão da comercialização de planos pelos ciclos de monitoramento." (2016, p. 55).
} 
A assimetria de informação é uma das principais falhas de mercado ensejadoras da regulação de um mercado gerencial. Nas lições de Vasconcellos:

\begin{abstract}
$\mathrm{Na}$ Teoria ou Economia da Informação, trabalha-se com a probabilidade de que alguns agentes detêm mais informação que outros, conferindo-lhes uma posição diferenciada no mercado, o que pode fazer com que não seja possível encontrar uma situação de equilíbrio (ou de ótimo) como nos modelos convencionais (2015, p. 183).
\end{abstract}

Na saúde suplementar, a assimetria da informação reduz a eficiência econômica do setor, uma falha de mercado que faz justifica a intervenção gerencial do Estado, a fim de se impedir que deste desequilíbrio entre os atores do setor resultem efeitos perversos a esta microeconomia estudada, com um maior poder de mercado de uns sobre os outros (GABAN, 2004, p. 260).

Os efeitos decorrentes da assimetria de informação são a seleção adversa e o risco moral, tendo a ANS o papel de atuar para fiscalizar, regular e controlar o setor para que não haja prejuízos sociais e econômicos para os atores deste segmento de mercado (SOFAL, 2012, p. 116).

A informação disponibilizada aos usuários de saúde suplementar, a fim de evitar os efeitos perversos da assimetria daquela, é um dos ótimos resultados econômicos trazidos pelos indicadores reunidos na NIP através das reclamações dos consumidores. Desta forma, conforme Brunetti, nestas situações o conhecimento da ação que está sendo tomada ou amenos o monitoramento das ações mútuas é de importância capital, sem o qual não é possível garantir que as partes estejam agindo conforme foi pré-acordado (2013, p. 21).

$O$ fato de a ANS ter desenvolvido uma ferramenta que serve também para o monitoramento de mercado, através de informações que independem do interesse dos regulados, sendo alimentados por reclamações dos beneficiários, traduz um instrumento de baixo custo para a busca de informação, sem problemas de captura do órgão regulador, como bem nos ensina Pinto Jr. e Pires:

Um dos maiores problemas a ser enfrentado pelo regulador setorial diz respeito à assimetria de informações entre este e a empresa regulada. Para que o agente regulador atue de forma a conseguir extrair da empresa a prestação do serviço de forma eficiente, este necessita de informações detalhadas sobre as atividades econômico-financeiras e operacionais das firmas. As melhores fontes de obtenção dessas informações são as próprias firmas reguladas, pois elas são as detentoras das informações consideradas relevantes. Entretanto, essa forma de adquirir informações pode levar ao chamado problema de captura do regulador. Além deste aspecto, a busca de informação é um 
processo oneroso para o órgão regulador e, na maior parte dos casos, não é do interesse dos regulados (2000, p. 2).

Conforme a norma em vigor, a NIP é constituída por três fases pré-processuais todas em ambiente exclusivamente eletrônico: intermediação preliminar, classificação da demanda e classificação residual de demanda. Na primeira fase, a operadora é notificada para que adote as medidas necessárias para a solução da demanda junto ao consumidor, no prazo de cinco dias úteis em questões assistenciais, seguido de mais cinco dias úteis par apresentação de resposta à ANS. Já a NIP não assistencial tem prazo de dez dias úteis para solução da demanda, finalização com cliente e retorno à ANS. Nos dois casos a OPS deve demonstrar a solução da demanda ou o não cabimento, nos termos da RN n. 388 (NAVARRO, 2016). A demanda é considerada como resolvida ao final desses prazos quando o reclamante informa a solução da questão, ou quando, mesmo após notificado, deixa de se manifestar sobre o caso.

Superada a fase de intermediação, as demandas supervenientes seguem para a denominada fase de classificação, onde podem se enquadrar nas seguintes hipóteses, de acordo como estipulado no art. 14 da RN 388: sem indício de infração, resolvida por reparação voluntária e eficaz - RVE, não resolvida, beneficiário não pertencente à operadora reclamada, demanda duplicada, ausência de elementos mínimos de identificação, e agente regulado não responsável. Todas as demandas classificadas como não resolvidas são encaminhadas para os fiscais da ANS, que podem, ao recebê-las, efetuar sua reclassificação (terceira fase da NIP), motivadamente, para alterar inclusive a tipificação apontada anteriormente - art. 16 da RN 388.

Somente após a conclusão dessas etapas é que o órgão regulador instaura o processo administrativo sancionador, através da lavratura de auto de infração, para apurar a ocorrência de infração a dispositivos legais ou infralegais disciplinadores do mercado de saúde suplementar. Esse processo administrativo, onde ocorre a apuração dos fatos, que segue o rito disposto na RN 388, pode, ao final, acarretar a aplicação de sanção ao regulado.

Trata-se, portanto, de medida regulatória que advém da fase pré-processual de monitoramento de mercado através das reclamações dos consumidores, como forma de se manter um mercado sadio e equilibrado, sem prejuízo aos direitos dos beneficiários de saúde suplementar por produtos inadequados colocados à disposição pelas OPS analisadas.

Através do denominado Programa de Monitoramento da Garantia de Atendimento, a ANS pretende averiguar a capacidade de atendimento das operadoras de planos de saúde das demandas assistenciais de seus beneficiários. Criado como forma de analisar o cumprimento das regras dispostas na RN 259, que institui os prazos máximos de atendimento, o programa, desde sua criação, pela Instrução Normativa n. 38/2012, sempre utilizou as reclamações de usuários registradas via NIP como subsídio, sendo que, após duas reformas nos normativos, 
estabeleceu-se a NIP como única fonte de dados, através da edição da Instrução Normativa n. 48 de 2015.

Ao estabelecer prazos máximos para atendimento das demandas assistenciais, a ANS buscou uma forma de medir a suficiência da rede de prestadores de serviços de saúde dos produtos comercializados pelas operadoras. A lógica estabelecida foi a de que haveria prestadores suficientes se todos os clientes fossem atendidos em determinado período. Para checagem desse cumprimento, foi preciso estabelecer de que maneira as reclamações dos usuários seriam calculadas, e quais delas, através do estabelecimento de um indicador e da classificação das operadoras em faixas.

Dessa forma, após a compilação dos dados das reclamações, é aplicada a fórmula do indicador do monitoramento, que é anexo da instrução normativa, e as operadoras classificadas na faixa 03 podem ser proibidas de comercializar determinados planos de saúde, e, ainda, ter decretado o regime especial de direção técnica.

Contudo, a suspensão não atinge a carteira inteira da empresa. As reclamações são consideradas nos produtos específicos em que mais ocorreram. Assim, por exemplo, se muitos beneficiários do Plano Alpha Plus da Operadora Exemplo S/A reportam dificuldade de atendimento, é esse plano específico que fica proibido de receber novos clientes - dada a premissa de que não está conseguindo atender no prazo sequer os que lá já estão. São consideradas exceções a inclusão de dependentes e casos de aposentados e demitidos.

Trimestralmente, são consideradas as reclamações assistenciais que tenham sido classificadas como não resolvidas (encaminhadas para inaugurar o processo administrativo sancionador) e como RVE - Reparação voluntária e eficaz, para cálculo do indicador - aqui já atualizada a nomenclatura utilizada na IN 48 à redação da RN 444 de 2019. Somente são consideradas as reclamações que passaram pelo ciclo completo da NIP e já estão devidamente classificadas no âmbito da fiscalização. As suspensões de comercialização de produtos duram três meses.

Nos últimos três anos (2017-2019), o programa suspendeu a comercialização de 430 (quatrocentos e trinta) produtos de 128 (cento e vinte oito) operadoras, de acordo com os dados disponibilizados no sítio da ANS. É certo que muitas operadoras se repetem nas listagens trimestrais, ou seja, não demonstram recuperação em sua capacidade de atendimento, o mesmo ocorrendo com seus respectivos produtos, de maneira que esses números espelham tais repetições.

Ao receber os dados diretamente dos beneficiários de planos de saúde, e utilizando-os de forma a mitigar os riscos a que estão sujeitos esses consumidores, a agência reguladora atua diminuindo sua própria assimetria de informação, uma vez que passa a ter conhecimento da capacidade de atendimento de operadoras e pode constatar se os dados por elas livremente informados condiz com a realidade de atendimento. 
Quando processa os dados e decide pela suspensão de comercialização, a ANS age para atenuar a falta de informações dos próprios beneficiários que forneceram as informações a ela. Isso porque o programa de suspensão é ostensivamente noticiado, cuidando para alertar aos consumidores sobre empresas e planos que não estão atuando conforme as regras legalmente instituídas.

Valida a suspensão o fato de apenas serem consideradas NIPs que já tenham cumprido todas as fases e onde se identificaram alta probabilidade de ocorrência de infração administrativa. Isso porque, em fase de intermediação, a operadora pode e deve apresentar toda sua argumentação sobre ocorrido, o que é devidamente considerado na fase de classificação. Dessa forma, se a reclamação ultrapassa essa etapa mantendo a chancela de não resolvida, há indícios suficientes para a abertura de processo sancionador. $\mathrm{O}$ mesmo pode ser aplicado às reclamações que são classificadas como RVE, já que estas, embora não sigam para eventual aplicação de sanção, são assim consideradas porque de fato houve falha, mas ela foi corrigida dentro de um prazo estipulado normativamente. Em suma, em ambos os casos é demonstrado o desequilíbrio no atendimento aos usuários.

Desta forma, a utilização da NIP como instrumento de monitoramento de mercado, apto a diminuir a assimetria de informação entre o regulador e os regulados, e também entre os atores deste mercado, revela-se legítimo e razoável, assim como o são a aplicação das medidas administrativas acautelatórias de suspensão da comercialização de planos e decretação do regime especial de direção técnica, em processo distinto e posterior, utilizando a ferramenta como subsídio.

Como dito, a aplicação dessas medidas objetiva evitar que uma operadora, que já não está conseguindo atender aos seus beneficiários, mas estes não possuem tal informação, aumente sua carteira de consumidores, potencializando seu risco de desatendimento, em detrimento da regulação do setor. Por certo, em tais hipóteses, é necessário prevenir, de imediato, grave dano ao interesse público, sob pena de se fazer letra morta a sistemática do Estado Gerencial Brasileiro e o relevante papel outorgado pela Constituição Federal às agências reguladoras.

Quanto ao método de avaliação das OPS por medianas, a partir da avaliação feita pela ANS através das demandas de reclamações de beneficiários recepcionadas pela ANS, que tenham como referência toda e qualquer restrição de acesso à cobertura assistencial, processadas no âmbito do procedimento da Notificação de Intermediação Preliminar - NIP, traduz-se como interessante método de classificação a partir das variáveis regulamentadas no art. $9^{\circ}$ da IN ANS no 48/2015, através da fórmula do cálculo do indicador das operadoras, que considera o número de beneficiários da empresa para relativizar o cálculo.

O programa do monitoramento considera critérios equivalentes, sendo que sempre haverá alguma empresa graduada acima da mediana. O critério comparativo, considerando o número de beneficiários, o porte da operadora e o tipo de atenção prestada observa o princípio da igualdade substancial (art. 5\%, caput, e I, da CRFB/88), pois classifica as operadoras, observando as suas peculiaridades, o que potencializa a eficiência administrativa na regulação entre 
semelhantes, exigindo sempre uma melhora de desempenho, com menores índices de reclamações de consumidores, a fim de se fornecer um melhor serviço no mercado de consumo.

Como resultado eficiente em termos de regulação microeconômica, observa-se as hipóteses narradas no art. 16 da IR 48/2015, com a possibilidade de aplicação das medidas de suspensão de comercialização dos planos e de decretação do regime especial de direção técnica, decorrentes da consolidação de avaliações, risco à qualidade ou à continuidade do atendimento à saúde dos beneficiários, também passíveis de extração da informação necessária com as reclamações contabilizadas nas NIPs. Essas ações pretendem manter um mercado saudável e não deletério aos consumidores de saúde suplementar, que precisam saber que poderão utilizar do seu plano quando necessitarem, a fim de evitar a morte ou adoecimentos sem o devido atendimento contratualizado.

Importante observar que a função de monitoramento do mercado da NIP, como forma de se reduzir a assimetria de informação, já foi questionada judicialmente pelas OPS, em processo coletivo do qual o Núcleo de Defesa do Consumidor da Defensoria Pública do Estado do Rio de Janeiro fez parte, e, ao final, chancelou-se acerca de sua legalidade e constitucionalidade perante o Poder Judiciário, sendo confirmada a validade do processo de acompanhamento e avaliação da garantia de atendimento dos beneficiários de planos de saúde efetuado pela Agência Nacional de Saúde Suplementar - ANS. ${ }^{4}$

Conclui-se com a confirmação de que a NIP é uma eficiente ferramenta de regulação, não somente como atividade de fiscalização, mas como fundamental insumo para programas de monitoramento do mercado de saúde suplementar.

\section{A NIP E A JUdiCIALIZAÇÃo DA SAÚdE SUPLEMENTAR - MODELO DE EFICIÊNCIA DE RESOLUÇÃO DE CONFLITOS}

O problema da judicialização da saúde suplementar é objeto de muitos estudos científicos, os quais serão abordados ao longo desta pesquisa.

Dentre as formas de solução dos problemas de consumo relativos à saúde suplementar, destaca-se a NIP, em razão da quantidade de casos solucionados através deste procedimento.

Não se pretende explorar outras formas de solução do excesso de judicialização da saúde suplementar neste trabalho, seja através de resoluções coletivas, decisões vinculativas, arbitragem ou outros métodos de pacificação social.

A lente desenvolvida aqui busca delimitar o campo de pesquisa para formas de resolução extrajudicial dos conflitos de saúde suplementar através de métodos de conciliação em seu sentido amplo.

O fenômeno da judicialização da saúde suplementar é expressivo pelo tamanho do número de usuários deste mercado:

\footnotetext{
${ }^{4}$ Processo no $0022317-66.2013 .4 .02 .5101$ (2013.51.01.022317-8)
} 
Sendo a saúde suplementar garantida constitucionalmente mediante a oferta de serviços de assistência privados, com o entendimento de que se aplicavam às demandas desta natureza o Código do Consumidor (CDC), rapidamente os usuários encontraram o caminho da judicialização para resolver suas reclamações9. E não são poucos. Em 2017, mais de 47 milhões de brasileiros possuíam planos e saúde (MOTTA e PIACSEK, 2019, p. 30).

O paradigma regulatório imposto pela ANS possui o potencial de reduzir a judicialização de demandas relativas à saúde suplementar, se bem compreendidos e aceitos pelos atores deste mercado, sendo a NIP um instrumento importante para se buscar o consenso da interpretação e da conscientização dos direitos relativos à saúde suplementar. Contudo, há uma ausência de informação acerca do papel das normas regulatórias da ANS em confronto com as demais normas do nosso sistema jurídico, que possuem o condão de se criar um incentivo patológico à judicialização, geradora de insegurança jurídica, aumento de custos administrativos e do preço dos planos de saúde, em sua consequência final (RAMALHO, 2015, p. 141 e 142).

A grande maioria das ações judiciais são de caráter individual, e são repetitivas, com matérias que são em sua maioria relativas à cobertura, como verificou SCHEFFER, no recorte paulista (2006, p. 133 e 134).

De acordo com os dados fornecidos pelo CNJ, o número de novos casos de assunto Plano de Saúde, relativos a Direito do Consumidor são da ordem de mais de 141 mil em 2017, 134 mil e 2018 e 136 mil em 2019. O que revela um alto número, aparentemente estável, de novas ações judiciais ano após ano. Revelando, pois, uma necessidade de implementação de um modelo efetivo de resolução de litígios da saúde suplementar. ${ }^{5}$

A implantação da NIP pela ANS substituiu a forma de o consumidor entrar em contato com a agência para resolver seus problemas, de uma maneira substancial. Embora o órgão regulador sempre tenha disponibilizado central de atendimento através de 0800, bem como atendimento presencial em núcleos espalhados pelo país, as reclamações recepcionadas geravam longos processos individualizados, onde não havia qualquer ferramenta que privilegiasse a resposta ágil ao consumidor reclamante.

Os resultados analisados da NIP demonstram uma eficiência irrefutável, conforme se verifica dos estudos produzidos pela própria ANS.

A Resolução Extrajudicial de Conflitos na ANS se dá por meio da Notificação de Intermediação Preliminar (NIP). A NIP consiste em instrumento que visa à solução de conflitos entre consumidores e

\footnotetext{
${ }^{5}$ Disponível:https://paineis.cnj.jus.br/QvAJAXZfc/opendoc.htm?document=qvw_l\%2FPainelCNJ.q vw\&host $=Q V S \% 40$ neodimio03\&anonymous $=$ true\&sheet $=$ shResumoDespFT. Acesso em 02 set 2020.
} 
operadoras de planos de saúde, em decorrência de demandas de negativa de cobertura assistencial. A NIP objetiva conferir um tratamento mais célere e eficaz às reclamações de consumidores à ANS. A mediação possibilita que a operadora repare sua conduta irregular, evitando-se, assim, a abertura de processo administrativo e judicial, com a resolução das reclamações. A NIP demonstrou grande potencial indutor corretivo de falhas do processo de trabalho das operadoras, possibilitando ações concertadas de mediação e de fiscalização indutora. A NIP alcançou índices de resolutividade (medida do total de reclamações que são finalizadas no âmbito da NIP sem necessidade de abertura de processo administrativo) de 65\%, 68,8\% e 78,4\%, nos anos de 2010, 2011 e 2012, respectivamente (BRASIL, 2014, p. 181)

Os dados acerca da resolutividade da NIP estão disponíveis ao público no sítio da ANS, sendo reproduzidos abaixo os referentes às reclamações de negativas de cobertura dos anos de 2019 e $2020^{6}$ :

Índice de resolutividade de conflitos sobre

Ao todo, 27.512 notificações

\footnotetext{
${ }^{6}$ Disponível em http://www.ans.gov.br/perfil-do-setor/dados-e-indicadores-do-setor. Acesso em 29 jul. 2020.
} 


\section{Notificação de Intermediação Preliminar - NIP}

(Brasil - 2020)

NIP - instrumento de mediação que visa à solução consensual de conflitos entre operadoras e beneficiários

\section{$93,0 \%$}

Índice de resolutividade de conflitos sobre negativas de cobertura

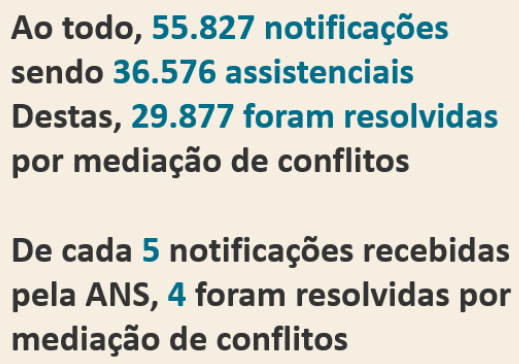

Conforme se vislumbra dos números de NIPs que ingressaram no sistema da ANS, sendo mais de 55 mil casos no ano de 2020, e obtiveram uma solução pacífica do conflito em um índice superior a 90\%, através deste canal público e gratuito de conciliação, podemos observar que a mesma se revela como um excelente mecanismo para a solução extrajudicial célere dos conflitos.

O procedimento da Notificação de Intermediação Preliminar - NIP consiste em um instrumento que visa à solução de conflitos entre beneficiários e Operadoras de planos privados de assistência à saúde - operadoras, inclusive as administradoras de benefícios, constituindo-se em uma fase pré-processual (Unes, 2018, P. 12).

O acumulado geral dos últimos anos demonstra com maior clareza a potência da ferramenta: 


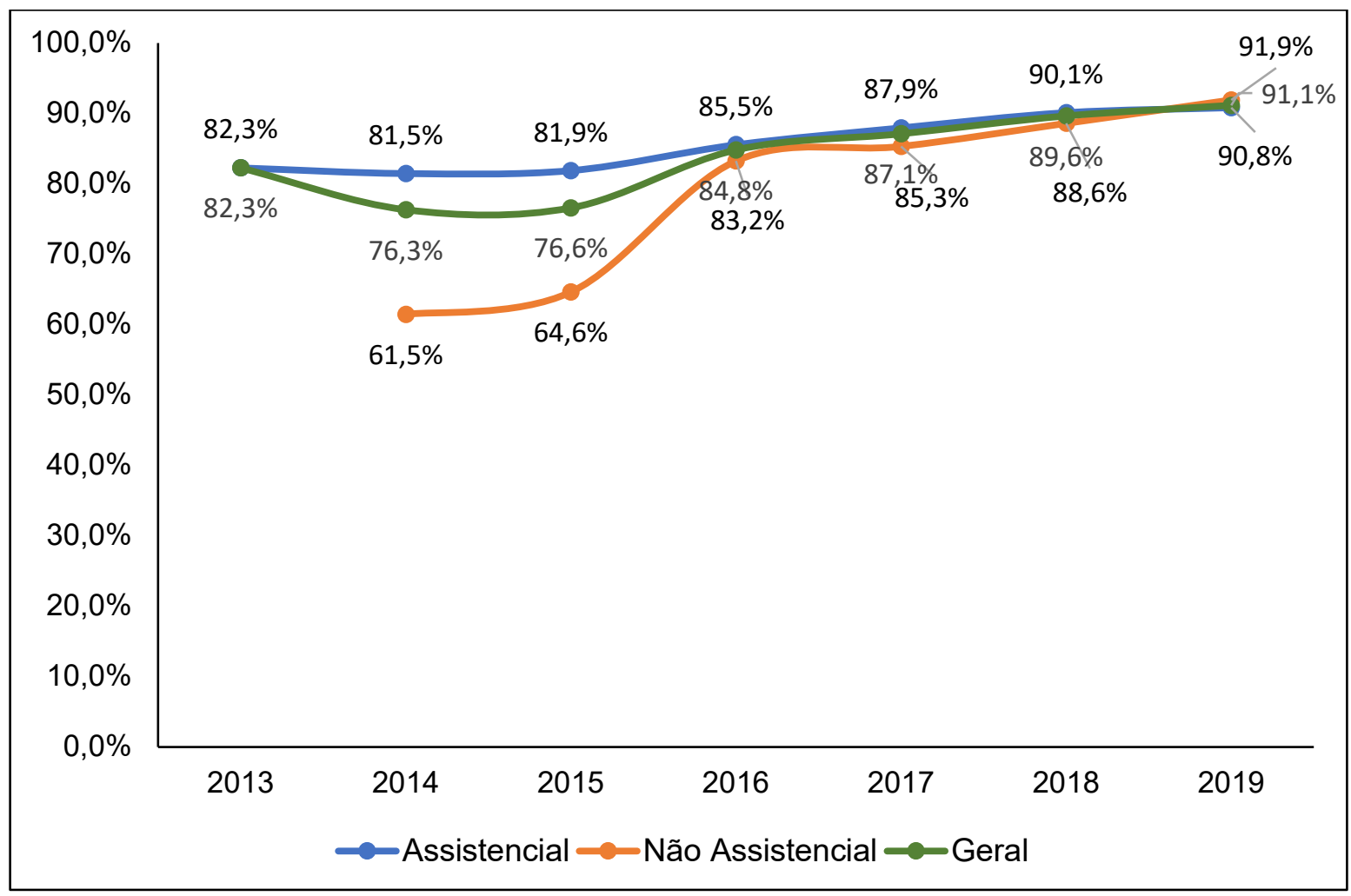

Com estes dados, não é possível extrair a conclusão de que as Operadoras dos Planos de Saúde não estão prestando um serviço adequado aos seus consumidores, mas sim que esta ferramenta de solução de conflitos está cada vez mais sendo utilizada pelos beneficiários, ao invés de ajuizarem imediatamente ações no Judiciário. Corrobora essa afirmação o aumento do número de reclamações recebidas pelo canal da ANS, considerando-se, principalmente, que não houve aumento no número de beneficiários de planos de saúde:

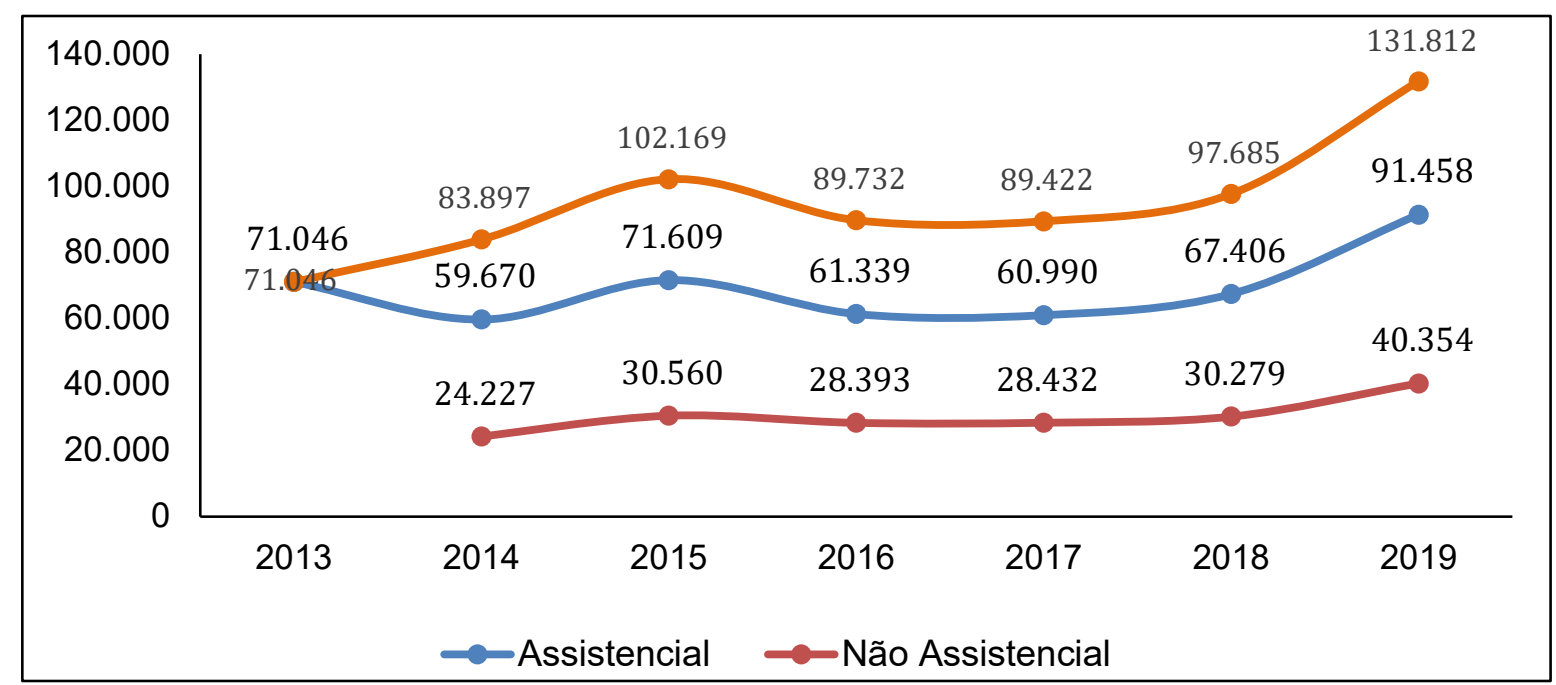

Fonte: Sistema de Informação de Fiscalização - SIF/ANS. Extraído em abril/2020. 


\begin{tabular}{|l|r|}
\hline ANO & Beneficiários em planos de assistência médica com ou sem odontologia \\
\hline 2014 & 50.531 .748 \\
\hline 2015 & 49.276 .145 \\
\hline 2016 & 47.631 .311 \\
\hline 2017 & 47.095 .598 \\
\hline 2018 & 47.095 .853 \\
\hline 2019 & 47.040 .159 \\
\hline
\end{tabular}

Fonte: Site da ANS - Dados gerais

Como se observa a partir dos dados, o número de pessoas com planos privados de assistência médica vem diminuindo ano a ano desde 2014, ao mesmo tempo em que se observa tendência de aumento de reclamações, sendo relevante o ano de 2019:

\begin{tabular}{|l|cc|c|}
\hline \multicolumn{1}{|c|}{ Natureza } & 2018 & 2019 & Variação(\%) \\
\hline Assistencial & 67.406 & 91.458 & $35,7 \%$ \\
Não Assistencial & 30.279 & 40.354 & $33,3 \%$ \\
\hline Total Geral & 97.685 & 131.812 & $34,9 \%$ \\
\hline
\end{tabular}

A partir dos dados, é possível constatar que os beneficiários de planos de saúde diminuíram no período avaliado, ao passo que o número de reclamações, apenas entre os anos de 2018 e 2019, aumentou em 34,9\%, revelando que possivelmente os usuários retornam ao canal da ANS, a partir de terem tido seus problemas resolvidos anteriormente.

Dada a celeridade do procedimento da NIP, a resposta é rápida e eficiente aos consumidores potencialmente lesados pelas Operadoras dos Planos de Saúde, permitindo que se afirme a eficiência deste instrumento de solução consensual do conflito, evitando-se a instauração de um número considerável de processos no Poder Judiciário.

Um levantamento de dados comparando os três principais órgãos públicos que atuam com reclamações de usuários de planos de saúde, demonstra, uma vez mais, a concentração na ferramenta NIP disponibilizada pela ANS: 


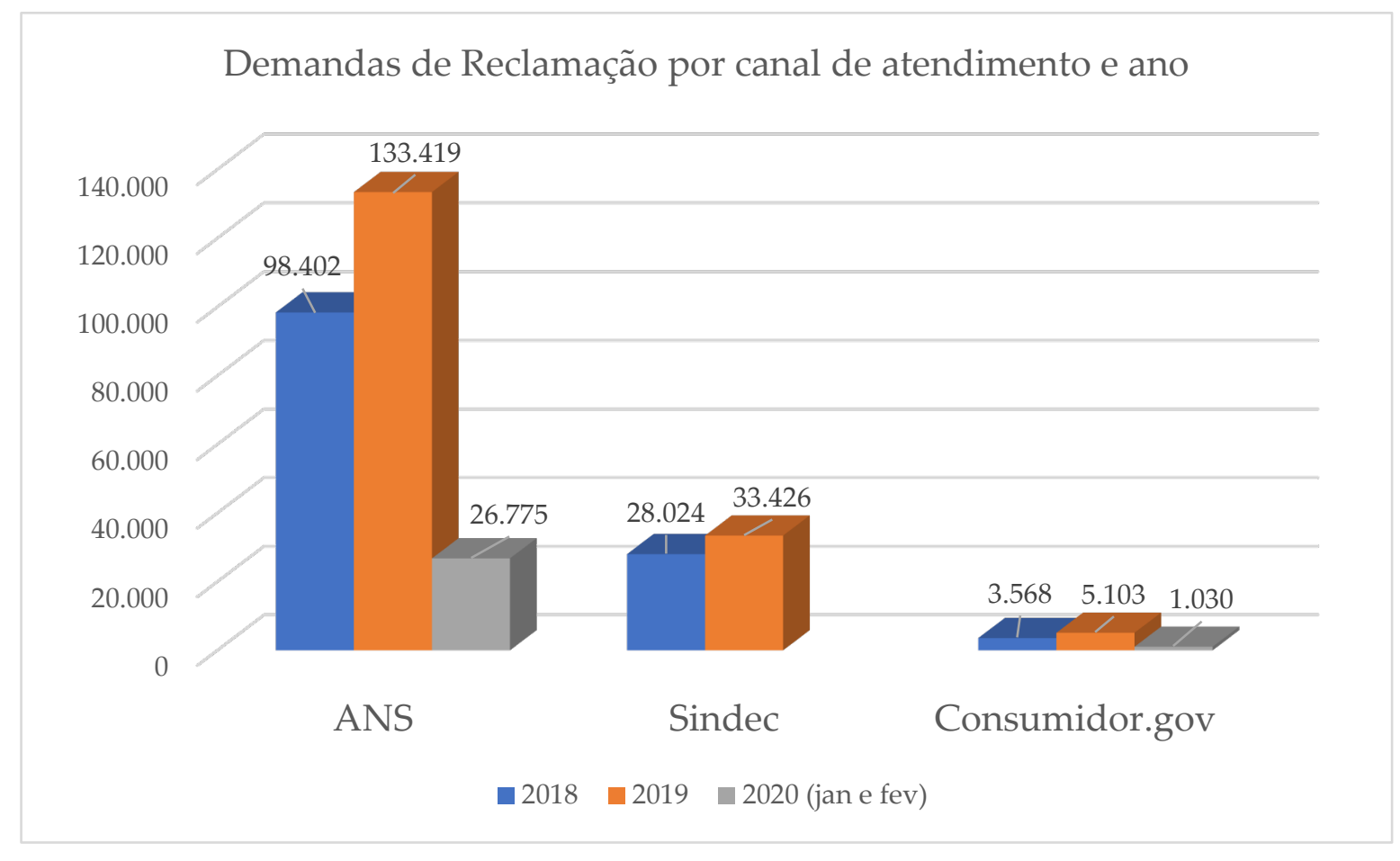

Fonte: Tabnet ANS, Boletim SINDED e Dados Abertos do Consumidor.gov

Nota: O Boletim SINDEC é anual portanto, não há informações sobre os primeiros meses de 2020.

Não obstante a grandiosidade dos números acima, ainda assim percebemos que as Operadoras dos Planos de Saúde são muito acionadas no Judiciário. Através de consulta aberta ao sítio do TJRJ, podemos observar o número crescente de ações judiciais sobre planos de saúde nos anos de 2017 a 2019 (respectivamente, 6.908, 7.184 e 8.062 novos casos submetidos à julgamento em segunda instância naquele órgão jurisdicional).

Comparando-se com a ferramenta disponibilizada pela Secretaria Nacional de Defesa do Consumidor: consumidor.gov ${ }^{7}$, não se verifica eficiência em termos de resolutividade e na razão de quantidade com relação à NIP. Somente a título de exemplo, observa-se que a OPS Amil, nos últimos 30 (trinta) dias estava com 158 reclamações finalizadas, com um índice de solução na faixa de 65,2\%; e o Bradesco Saúde, no mesmo período, com 83 casos finalizados e com o índice de solução em $72,3 \%$.

Mas revelam-se, ambas as ferramentas, como importantes instrumentos de resolução de conflitos entre consumidores e OPS, complementares, mas ainda não capazes de promover uma redução da judicialização da saúde suplementar, como bem verificado por Carvalho et al:

O presente artigo comparou diferentes elementos presentes nas reclamações registradas no canal consumidor.gov.br e no canal da ANS, concluindo-se que ambos exercem um importante papel

\footnotetext{
${ }^{7}$ Disponível em www.consumidor.gov.br. Acesso em 28/07/2020.
} 
social e, em alguma medida, desempenham papéis complementares entre si: o canal do consumidor recebe maior volume relacionado a cobranças indevidas e irregularidades com SAC, enquanto parcela substancial das reclamações tratadas pelo canal da ANS versa sobre a garantia de coberturas assistenciais. (...) Embora tais plataformas sejam instrumentos simples e gratuitos para a resolução de problemas envolvendo os serviços de planos de saúde, o uso isolado destas ferramentas não é suficiente para eliminar a excessiva utilização do Poder Judiciário como palanque adversarial. Isso se deve a diferentes hipóteses (a serem confirmadas por estudos futuros), dentre as quais podemos destacar: (i) a maior notoriedade e acessibilidade do Poder Judiciário; (ii) o imediatismo garantido pelas liminares judiciais; (iii) o conteúdo favorável das decisões, o que leva a mais judicialização; e (iv) a manutenção do Poder Judiciário como centro da tomada de decisão (2018, p. 391).

São muitos os fatores que contribuem para o alto grau de resolução de conflitos via NIP, que não encontram paralelo, por exemplo, na plataforma consumidor.gov, que também objetiva promover solução extrajudicial. Destacamos aqui o fato de que, não resolvida a questão, sendo uma conduta irregular do ponto de vista regulatório, através de posterior processo administrativo sancionador instaurado pela diretoria de Fiscalização da ANS, a OPS possivelmente será responsabilizada em âmbito administrativo, com aplicação de sanções, sendo a mais recorrente a pecuniária. Além da contabilização negativa para fins de monitoramento do mercado, que pode resultar nas medidas de suspensão de comercialização de novos produtos até que seja equilibrada sua situação no mercado, a NIP também influencia outras relevantes atividades regulatórias que não foram abordadas nesse artigo: a quantidade de reclamação das operadoras é usada no cálculo do indicador de fiscalização, que, a cada seis meses, pode incluir a empresa no programa de Intervenção Fiscalizatória, uma atuação proativa e mais contundente da ANS; o número de reclamações de beneficiários é o insumo para o cálculo do Índice Geral de Reclamações - IGR, que fica disponibilizado no site da Agência para consulta por parte dos consumidores sobre a posição das operadoras nesse ranking; a NIP é insumo do programa de monitoramento do risco assistencial das operadoras; e, por fim, também é componente do indicador do Índice de Desempenho da Saúde Suplementar - IDSS, uma importante ferramenta que permite a comparação das operadoras de planos de saúde, com o objetivo de fomentar a concorrência. Para além do ambiente regulatório, podemos afirmar que, para as empresas, há redução ou ao menos contenção de custos administrativos e operacionais na resolução de conflitos com seus usuários de maneira rápida e extrajudicial.

Há, dessa forma, incentivos positivos e negativos para que as operadoras resolvam de maneira eficaz os problemas do consumidor recepcionados pela ANS, 
através da NIP, em que pese serem matérias restritas às normas regulatórias e aos contratos firmados entre as partes.

A ferramenta implementada e desenvolvida pela ANS poderia ser ampliada para outras zonas de não regulação e abrangência da Agência, como também para outros setores da economia, de maneira a repetir os índices de solução aproximados a $100 \%$ no setor de saúde suplementar através da NIP, contribuindo, dessa forma, para a efetiva redução da judicialização dos conflitos no país.

\section{CONCLUSÃO}

O presente artigo confirma a afirmação de que a NIP é um instrumento regulatório com múltiplas funções, tendo sido destacadas as funções de resolução de conflitos da saúde suplementar e a de diminuição da assimetria de informações entre a ANS e as Operadoras de Planos de Saúde (OPS), através do monitoramento do mercado a partir das reclamações dos consumidores.

Foi confirmada a hipótese defendida neste trabalho, de que a Notificação de Intermediação Preliminar é um modelo de sucesso a título de solução extrajudicial do conflito e de mecanismo de insumo regulatório por possuir incentivos ímpares para as questões conflituosas postas a sua análise, dentro de seu escopo de abrangência.

A fórmula regulatória desenvolvida pela ANS se demonstrou eficiente, do ponto de vista jurídico e regulatório. Além de também ter se revelado como um modelo não oneroso de ser implementado, e independente da vontade das empresas reguladas para se ter sucesso. O que demonstra um bom resultado da conduta dos administradores públicos da ANS neste objetivo pretendido.

(...) os administradores públicos devem ser capazes de administrar democraticamente e gerenciar a participação das comunidades. A competência política para conciliar demandas sociais e conviver com as relações de poder entre estado e sociedade precisa ser aliada à capacidade técnica para definir prioridades e metas, formular estratégias e gerir recursos escassos (KEINERT, T.; Os Paradigmas da Administração Pública no Brasil (1900 - 92). Revista de Administração de Empresas, v. 34, n. 3, p. 41-48. 1994)

Através da NIP é possível reduzir a falha de mercado de assimetria das informações, seja perante o consumidor, seja perante o órgão regulador, o que revela a eficiência da medida regulatória implementada também para este fim, monitorando adequadamente o setor, a partir de informações disponibilizadas pelos beneficiários.

Desta maneira, o incentivo para que as OPS resolvam extrajudicialmente os conflitos com os consumidores deve ser melhor analisado para poder ser ampliado para outras áreas não reguladas, com outras ferramentas criadas ou aperfeiçoadas, sem prejuízo de sua replicação para outros áreas das relações de consumo, de 
maneira a se aproximar dos índices de resolução de conflitos acima de 90\%, como se verifica no setor de saúde suplementar através da Notificação de Intermediação Preliminar.

O presente estudo conclui que a atuação da ANS na área de resolução extrajudicial de conflitos e de monitoramento do mercado deve ser reforçada e prestigiada. Não só para se coibir novas práticas abusivas no setor como também para desafogar o Poder Judiciário, atolado de demandas de consumo relativos à saúde suplementar.

\section{REFERÊNCIAS}

BRASIL. Ministério da Saúde (MS). Agência Nacional de Saúde Suplementar (ANS). Resolução extrajudicial de conflitos entre consumidores e operadoras de planos de saúde. Escola Nacional de Administração Pública (Enap). Brasília. 2014 .

BRUNETTI, Lucas. Assimetria de informação no mercado brasileiro de saúde suplementar: testando a eficiência dos planos de cosseguro. 2013. Tese de Doutorado. Universidade de São Paulo.

CARVALHO, Rafaela M.; PORTO, Antônio José Maristrello; RAMALH, Bruno Araujo. Papel institucional dos canais de reclamação para a resolução extrajudicial de conflitos sobre planos de saúde: uma análise comparada. Revista brasileira de políticas públicas, 2018.

GABAN, Eduardo Molan. Regulação econômica e assimetria de informação.

Revista de Direito Constitucional e Internacional. São Paulo, v.12, n.46, p.233289, jan./mar. 2004.

OLIVEIRA, Rosa Maria Rodrigues de. Projeto BRA 05/036. UTILIZAÇÃO DE MEIOS DE RESOLUÇÃO EXTRAJUDICIAL DE CONFLITOS NO ÂMBITO DE SERVIÇOS REGULADOS POR AGÊNCIAS GOVERNAMENTAIS.

Brasília: Ministério da Justiça, Secretaria da Reforma do Judiciário, 2012.

DA MOTTA, Marcia Vieira; DA MOTTA PIACSEK, Monica Vieira. Planos de Saúde: entendimento jurisprudencial dominante nos Tribunais estaduais brasileiros. Saúde, Ética \& Justiça, v. 24, n. 1, p. 29-43, 2019.

KEINERT, T.; Os Paradigmas da Administração Pública no Brasil (1900 - 92). Revista de Administração de Empresas, v. 34, n. 3, p. 41-48. 1994.

MIRALDO, Claudio de Oliveira. A utilização de sistema de informação para gestão das demandas dos beneficiários de operadoras de saúde suplementar, 
como estratégia frente à regulação do setor e a Notificação de Intermediação Preliminar (NIP). 2016. Tese de Doutorado.

NAVARRO, Filipe Veras. As mudanças advindas da regulação das ouvidorias das operadoras de planos privados de saúde: estudo de caso na Unimed Fortaleza. Universidade Federal do Ceará. 2016.

PINTO JR, Helder Q. et al. Assimetria de informações e problemas regulatórios. Rio de Janeiro: Agência Nacional do Petróleo, Nota Técnica, n. 10, p. 217-260, 2000.

RAMALHO, Bruno Araujo. A Interface institucional entre a ANS e o Poder Judiciário: análise de acórdãos sobre a cobertura de emergências médicas em planos de saúde. R. Dir. sanit., São Paulo v.17 n.1, p. 122-144, mar./jun. 2016.

SALVATORI, Rachel Torres; VENTURA, Carla A. Arena. A Agência Nacional de Saúde Suplementar-ANS: onze anos de regulação dos planos de saúde. Organ. Soc, p. 471-488, 2012.

SCHEFFER, Mario César. Os planos de saúde nos tribunais: uma análise das ações judiciais movidas por clientes de planos de saúde, relacionadas à negação de coberturas assistenciais no Estado de São Paulo. 2006. Tese de Doutorado. Universidade de São Paulo.

SOFAL, Delgado. A saúde suplementar brasileira e as assimetrias de informação: risco moral e seleção adversa. Revista da AMDE, v. 9, n. 1, p. 88-132, 2012.

UNES, André Luis Fortes. Por que mudar? a "virada de jogo" na fiscalização da ANS. Dissertação de Mestrado. FGV-Rio, 2018.

VASCONCELLOS, Marco Antonio Sandoval de. Economia: micro e macro: teoria e exercícios, glossário com os 300 principais conceitos econômicos. $6^{a}$ ed. São Paulo. Atlas. 2015. 